\title{
Análisis económico del régimen jurídico de la protección de usuarios de las telecomunicaciones en Colombia ${ }^{1}$
}

\author{
Ángela Bejarano DaZA²
}

\section{RESUMEN}

El impacto de la regulación sobre el cumplimiento de las normas que protegen los derechos de los usuarios de comunicaciones no es muy positivo. A pesar de que las multas impuestas a los proveedores de servicios disidentes de la regulación de protección de los derechos de los usuarios sean cada vez más altas y reiterativas, estos siguen prestando servicios sin calidad y aún es evidente el irrespeto de los derechos de los usuarios. En el sector de las telecomunicaciones, este fenómeno se fundamenta en el comportamiento clásico y racional de los proveedores de servicios, quienes como agentes del mercado y en ejercicio de la competencia, dentro de sus estrategias de juego, el juego dominante ${ }^{3}$ es su preferencia por el incumplimiento de la Regulación de Protección de los Derechos de los Usuarios de los Servicios de Comunicaciones, dado que el costo (las sanciones pecuniarias) nunca será mayor al beneficio reportado con el incumplimiento (utilidades).

Palabras Clave: Derecho administrativo sancionador, análisis económico del derecho, derecho del consumo, regulación económica.

1 Fecha de recepción: 4 de octubre de 2016. Fecha de aprobación: 30 de octubre de 2016. Para citar el artículo: Bejarano, A. (2016). Análisis económico del régimen jurídico de la protección de usuarios de las telecomunicaciones en Colombia, en Revista Con-texto n. ${ }^{\circ}$ 46, pp. 85-116. DOI: https://doi.org/10.18601/01236458.n46.07

2 Abogada de la Universidad Externado de Colombia, especialista en derecho comercial y derecho de la empresa de la Universidad del Rosario, magister en Derecho Económico de la Universidad Externado de Colombia. Correo electrónico: angela.bejarano@wlegalb.co

3 HurwiCZ, L. But will guard the guardians?, en The American Economic Review, 2008, n. ${ }^{\circ} 98$ (3), pp. 577-585. 


\section{ECONOMIC ANALYSIS OF THE LEGAL REGIME OF TELECOMMUNICATIONS USERS' PROTECTION IN COLOMBIA}

\section{ABSTRACT}

The impact of regulation on the compliance of the rules protecting the rights of communication users is not very positive. Although the fines imposed to offenders are increasingly high and repetitive, they continue to provide services without quality and even disrespecting the rights of users. In the telecommunications sector, this phenomenon is based on the classic and rational behavior of service providers, who in selecting their game strategies, will prefer to the breach of Regulation, since the cost (financial penalties) never is greater than the profit reported with the infringements (utilities).

Keywords: Administrative law sanctions, law and economics, consumer law, economic regulation.

\section{INTRODUCCIÓN}

La regulación del consumo se encuentra edificada entorno a la asimetría de la relación jurídica y comercial entre consumidor y productor o proveedor. El concepto de consumo responsable busca que el consumidor desempeñe un papel protagónico y decisivo en la economía, y que en ejercicio de su poder de decisión, a través de suficientes herramientas de información, pueda elegir a los proveedores de servicios que le presten una óptima calidad, de conformidad con sus propios intereses o preferencias.

De tal modo que el consumo racional esté acompañado de un deber de responsabilidad al momento de elegir el proveedor de servicios, para, de esta manera, reducir los diferentes costos de transacción que llegan a impedir elegir al mejor. Es claro que las normas de protección a los consumidores, alrededor del mundo, buscan reducir la asimetría de información, para que consumidores informados de las calidades y propiedades de los bienes que van a adquirir decidan si es o no conveniente adquirirlos.

Sin embargo, no sucede lo mismo con el consumo de servicios, dado que los consumidores modernos adquieren, además de bienes, servicios. Trasladándonos al sector de las telecomunicaciones, por ejemplo, no se produce un bien que no esté atado a un servicio; por ende, la regulación de protección a los consumidores está soportada en un mercado de bienes tangibles y transables, mas no en la transacción de servicios. Por ello, es a los consumidores de servicios, llamados por la regulación colombiana "usuarios", a quienes se debe fortalecer en su poder, capacidad y derecho de elección.

En este escenario, y teniendo en cuenta que las entidades de control hacen su mayor esfuerzo por conminar a los proveedores de servicios, entre los cuales están los servicios públicos esenciales de los fines del Estado para lograr el bienestar social, es necesario precisar que el arma fundamental, que en algunas ocasiones, y en algunos sectores, pue- 
de llegar a ser la única con la que cuentan estas entidades de control, contenida en las diferentes regulaciones, es la sanción pecuniaria.

Al respecto, es preciso tener cuenta diferentes recomendaciones dadas por organizaciones internacionales tales como la Organización para la Cooperación y el Desarrollo Económico -en adelante $\mathrm{OCDE}^{4}$-, respecto a la eficacia de la regulación, donde podemos preguntarnos si la regulación vigente en materia de prestación de servicios, incluidos los servicios públicos, es eficaz, es decir, si realmente cumple los cometidos para lo cuales se creó al menor costo posible, entre ellos, la protección de los derechos de los usuarios. En el desarrollo de la presente monografía, vamos a responder dicho interrogante, pudiendo adelantar, como lo demostraremos más adelante, que la respuesta es negativa, pues es notoria la insatisfacción generalizada de los consumidores, o mejor, usuarios de servicios.

Según las recomendaciones de la OCDE, debe analizarse el cumplimiento de los siguientes principios, mediante un juicio ex ante y ex post a la regulación que se propone, con el fin de medir la eficacia de las medidas como mecanismo idóneo e inequívoco para superar la falla que inspira la regulación:

“... 1. Necesidad

El principio de necesidad opera antes de la implementación de una política. Señala que los productores de normas solo deben proponer una regulación si esta es pertinente para resolver un determinado problema público..."

"... 2. Proporcionalidad

... Así, una vez se establezca que la norma es necesaria, según el principio de necesidad, habría que establecer si sus beneficios son mayores que sus costos/desventajas..."

"... 3. Transparencia

Los afectados e interesados en una regulación pueden participar, esto es, concocer, debatir y retroalimentar sobre una propuesta normativa, se mejora el proceso de conocimiento respecto a un determinado problema, lo que facilitará el diseño de una regulación más efectiva y también imparcial.

"... 4. Accesibilidad

4 "Fundada en 1961, la Organización para la Cooperación y el Desarrollo Económicos (OCDE) agrupa a 34 países miembros y su misión es promover políticas que mejoren el bienestar económico y social de las personas alrededor del mundo. La OCDE ofrece un foro donde los gobiernos puedan trabajar conjuntamente para compartir experiencias y buscar soluciones a los problemas comunes. Trabajamos para entender qué es lo que conduce al cambio económico, social y ambiental. Medimos la productividad y los flujos globales del comercio e inversión. Analizamos y comparamos datos para realizar pronósticos de tendencias. Fijamos estándares internacionales dentro de un amplio rango de temas de políticas públicas" (OCDE). 
Una regulación es accesible si logra ser comunicada adecuadamente y si logra ser conocida por aquellos a quienes afecta. Este principio se situa en la fase posterior al diseño de la norma.

"... 5. Simplicidad

... este principio busca que la regulación tenga el nivel de detalle necesario para ser entendida fácilmente por los destinatarios. Con este principio se resalta el valor de la claridad y de lo simple.

“...6. Accountability

Este principio está planteado en términos de responsabilidad y de rendición de cuentas, la mejora regulatoria requiere que los destinatarios estén en capacidad de identificar quién es la autoridad pública que originó la regulación. También supone garantizar que dicha autoridad deba informar sobre las dificultades en la implementación de las regulaciones..." ${ }^{15}$

En ese sentido, se realizará un análisis de la necesidad de la regulación, así como de la proporcionalidad en materia de normas que buscan la protección de los derechos de los usuarios de las comunicaciones, intentando proponer que la regulación albergue medidas alternas a la sanción pecuniaria, para que se logre persuadir a los proveedores de servicios a que cumplan con los niveles de calidad que ofrecen y que son exigidos por sus usuarios como contraprestación de sus pagos. Por lo tanto, dado que los proveedores de servicios invierten la mayoría de su presupuesto en publicidad para lograr reconocimiento y posesión del mercado, lo que se debería atacar es su reputación.

La regulación debe estar dirigida a brindar herramientas que reduzcan la asimetría de información de los usuarios a la hora de elegir a sus proveedores de servicios; esto porque los usuarios no conocen cuáles proveedores, dentro de los pocos que existen, han prestado servicios con un grado de calidad de óptimo a deficiente. Así, los usuarios de servicios no cuentan con herramientas útiles que les permitan ejercer su derecho de elección del respectivo proveedor de manera informada, en ejercicio de un consumo responsable y sin racionalidad limitada a la hora de elegir el proveedor de servicios.

También tenemos que es posible que la restricción de acceso a la información esencial para los usuarios de servicios se quebrante al generar herramientas de información que le permitan fácilmente identificar las calidades de prestación de los servicios de los pocos, pero diferentes, proveedores de servicios.

La propuesta que se plantea, y que tiene como objeto reducir la asimetría de información que lleva a los usuarios de servicios a efectuar una selección adversa de su proveedor de servicios, consiste en generar un canal de información que guíe al usuario para que conozca las calidades de los servicios prestados, a través de sistemas de califi- 
cación donde se gradúe la calidad de los diferentes servicios que se prestan, construidos teniendo en cuenta los diferentes intereses de los consumidores o usuarios a la hora de contratar sus servicios.

Este sistema de calificación daría suficientes herramientas de información a los usuarios de los servicios que más se adecuen a sus preferencias, metodología que podría aplicarse en todos los sectores de la economía donde se prestan servicios: telecomunicaciones, servicios públicos, salud, transporte, educación, etc.

Así podría el consumidor, después de ser objetivo de una campaña de divulgación de la importancia de su deber de ejercer un consumo responsable, forjar una coerción significativa en la exigencia de calidad en la prestación de los diferentes servicios que contrata según sus propias necesidades.

Para lograr esto, el presente trabajo se encuentra divido en tres partes, donde tenemos una primera parte relacionada con los principios del derecho administrativo sancionador y el régimen jurídico de telecomunicaciones en Colombia y su protección a los usuarios.

Una segunda parte, encaminada a realizar un análisis económico del derecho administrativo sancionador como punto transcendental para definir el problema planteado y la propuesta de solución.

Por último, tenemos una propuesta de solución al problema detectado, con base en herramientas que pueden, en cierta medida, contribuir a la eficacia en el cumplimiento de la regulación y, de paso, hacer más efectiva la protección de los usuarios de las comunicaciones.

\section{INCENTIVOS DE LA REGULACIÓN EN EL SECTOR DE LAS TELECOMUNICACIONES EN COLOMBIA}

El objetivo del presente acápite es analizar la eficacia de la regulación para incentivar a los proveedores de servicios de comunicaciones al cumplimiento de la regulacion existente en materia de protección de los derechos de los usuarios de comunicaciones, desde el punto de vista del análisis económico del derecho.

Lo anterior, con el fin de encontrar soluciones eficientes que den suficientes herramientas a los usuarios de servicios de comunicaciones para que, en ejercicio de su derecho de elección, exijan una mejor calidad de los servicios.

Para el desarrollo de lo anteriormente planteado, a través de un método inductivo, se partirá del estudio particular de la regulación actual en materia de comunicaciones, con el fin de analizar la eficiencia de esta y, específicamente, determinar si la regulación existente conmina al cumplimiento, por parte de los proveedores de servicios de comunicaciones, de las normas de protección de los derechos de los usuarios de comunicaciones. Para esto, haremos uso del análisis económico del derecho, con el propósito de encontrar soluciones eficientes que le den suficientes herramientas a los usuarios de servicios de comunicaciones para que, en ejercicio de su derecho de elección, exijan una mejor calidad de los servicios. 
Con este fin, es preciso cuestionarse lo siguiente:

¿La regulación en materia de protección a usuarios de servicios de comunicaciones incluye suficientes herramientas de información que permitan reducir los costos de transacción de los usuarios para poder acceder al proveedor de servicios de comunicaciones que más se adecue a sus preferencias?

¿Los usuarios de los servicios de telecomunicaciones cuentan con suficientes herramientas de información para poder elegir, dentro de los diferentes proveedores de servicios de comunicaciones, al mejor?

¿El sistema sancionatorio que dispone la Ley 1341 de 2009 conmina a los proveedores de servicios de comunicaciones al cumplimiento de las normas y el respeto de los derechos de los usuarios?

Para resolver lo anterior, debemos partir por describir detalladamente el régimen de protección de usuarios de servicios de comunicaciones regulado por la Comision de Regulación de Telecomunicaciones.

\subsection{Descripción del Régimen de Protección de Usuarios de los Servicios de Comunicaciones}

En primer lugar, es preciso mencionar que el Régimen de Protección de Usuarios de los Servicios de Comunicaciones encuentra su fundamento legal en la Ley 1341 de 2009, que dispone que, en lo referido a servicios de comunicaciones, el régimen será el dispuesto en la regulación que, en materia de protección al usuario, expida la Comisión de Regulación de Comunicaciones, y en el régimen general de protección al consumidor y sus normas complementarias, en lo no previsto en aquella ${ }^{6}$.

En este orden de ideas, y teniendo en cuenta que la regulación aplicable en materia de protección al usuario expedida por la Comisión de Regulación de Comunicaciones es el propio de la Resolución 3066 de 2011, "Régimen integral de protección de los derechos de los usuarios de los servicios de comunicaciones", es necesario señalar que el ámbito de aplicación consagrado en este régimen es el siguiente:

"Artículo 1. Ámbito de aplicación. El presente régimen aplica a las relaciones surgidas entre los proveedores de servicios de comunicaciones, de que trata la Ley 1341 de 2009, y los usuarios, a partir del ofrecimiento y durante la celebración y ejecución del contrato de prestación de servicios de comunicaciones, en cumplimiento de la ley y el régimen vigente...".

Ahora bien, la Superintendencia de Industria y Comercio, en ejercicio de sus facultades legales, y en especial de las conferidas por la Ley 1341 de 2009 y el artículo 13 del

6 Ley 1341 de 2009. "Artículo 53. Régimen jurídico. El régimen jurídico de protección al usuario, en lo que se refiere a servicios de comunicaciones, será el dispuesto en la regulación que en materia de protección al usuario expida la CRC y en el régimen general de protección al consumidor y sus normas complementarias en lo no previsto en aquella...". 
Decreto 4886 de 2011, tiene la potestad de sancionar a los proveedores de servicios de comunicaciones cuando se encuentre ante el surtimiento de una investigación administrativa por el presunto quebrantamiento, por parte del proveedor, de las disposiciones normativas en materia de protección de los derechos de los usuarios de los servicios de comunicaciones.

Consecuentemente, el legislador previó, en el artículo 65 de la Ley 1341 de 2009, que cualquier incumplimiento o violación de las disposiciones legales, reglamentarias o regulatorias en materia de telecomunicaciones produciría directamente la imposición de sanciones que pueden variar, dependiendo de la gravedad de la falta, el daño producido, la reincidencia en la comisión de los hechos y la proporcionalidad entre la falta y la sanción.

Sin perjuicio de lo anterior, debe aclararse que el artículo 44 de la Ley 1753 de 2015 modificó dicho artículo, y estableció lo siguiente:

"Artículo 65. Sanciones. Sin perjuicio de la responsabilidad penal o civil en que pueda incurrir el infractor, la persona natural o jurídica que incurra en cualquiera de las infracciones señaladas en el artículo 64 de la presente ley, será sancionada, además de la orden de cesación inmediata de la conducta que sea contraria a las disposiciones previstas en esta ley, con:

\section{Amonestación.}

2. Multa hasta por el equivalente a dos mil (2.000) salarios mínimos legales mensuales para personas naturales.

3. Multa hasta por el equivalente a quince mil (15.000) salarios mínimos legales mensuales para personas jurídicas.

4. Suspensión de la operación al público hasta por dos (2) meses.

5. Caducidad del contrato o cancelación de la licencia, autorización o permiso".

No obstante, el artículo 44 de la Ley 1753 de 2015 se aplicará a la investigaciones que se inicien con posterioridad a la entrada en vigencia de esta ley, es decir, con efectos ultractivos.

En lo que concierne a la graduación de la sanción que la Superintendencia de Industria y Comercio realiza en virtud de la facultad sancionatoria legalmente atribuida, ella obedece, principalmente, a una facultad discrecional que no es absoluta, es decir, no depende de la aplicación de criterios subjetivos de acuerdo con el funcionario de turno, sino, todo lo contrario, obedece a criterios objetivos previamente establecidos en aplicación de los principios anteriormente definidos.

En efecto, el monto de la sanción que se aplica en cada caso particular se encuentra gobernado por criterios definidos legalmente en el artículo 66 de la Ley 1341 de 2009, los cuales son: (i) la gravedad de la falta, (ii) el daño producido, (iii) la reincidencia en la comisión de los hechos y (iv) la proporcionalidad entre la falta y la sanción. 
Ahora bien, tal y como se indicó, el primer objetivo específico de este trabajo es analizar la eficacia de las herramientas regulatorias para conminar a los proveedores de servicios de comunicaciones a cumplir con las normas de protección de usuarios de estos servicios. Para ello, en primer lugar, se señalará cuál es el concepto de calidad de servicio definido por la Unión Internacional de Comunicaciones, el cual fue acogido y desarrollado en Colombia por la Comisión de Regulación de Comunicaciones.

Partiendo de lo anterior, el segundo objetivo específico será establecer herramientas de información para los usuarios de servicios de comunicaciones que permitan reducir asimetrías de información respecto de la calidad de los servicios y, a su vez, generar incentivos de cumplimiento de estas normas a los proveedores de servicios de comunicaciones.

En este sentido, se determinarán cuáles son los principales bienes jurídicos que la Superintendencia de Industria y Comercio, ante la culminación de investigaciones administrativas, pretende proteger, ya sea que se hayan iniciado dichas investigaciones de oficio o a petición de parte, y donde la autoridad ha ejercido su facultad sancionatoria al encontrar la vulneración al Régimen de Protección de Usuarios de Servicios de Comunicaciones, contemplado, principalmente, en la Resolución 3066 de 2011 y sus correspondientes modificaciones -Resolución 3530 de 2012, Resolución 4295 de 2013, Resolución 4025 de 2014 y Resolución 4444 de 2014 expedidas por la Comisión de Regulación de Comunicaciones (CRC)-.

En este contexto, se deben clasificar en dos grupos las normas de protección de los intereses de los usuarios de telefonía móvil en Colombia:

i) El primero está relacionado con los deberes de los proveedores de servicios de comunicaciones de prestar un servicio con calidad, es decir, de forma continúa y eficiente.

Así pues, en caso de existir falta de disponibilidad de la red, así como la deficiente prestación de los servicios de voz a través de redes móviles, en razón de los eventos de caídas de llamadas, sin que medie voluntad del usuario, la Comisión de Regulación de Comunicaciones estableció, a traves de la Resolución 4296 de 2013, un Régimen de Compensación Automática, en el cual definió las condiciones bajo las cuales el usuario debe recibir la compensación.

Si bien la intención del ente regulador en Colombia es que opere una compensación sin que medie solicitud del usuario, para que haya una respuesta más rápida, es preciso resaltar que el ejercicio de vigilancia y control sobre el cumplimiento estricto de esta regulación es muy díficil, pues el soporte del indicador puede llegar a ser manipulado por el vigilado, y se desecha el soporte probatorio del usuario.

Dicho lo anterior, al centrarse en el concepto de "calidad de los servicios de comunicaciones", se resaltan en la regulación dos aspectos fundamentales: tanto la calidad en la prestación del servicio como la calidad en la atención a los usuarios; este último, principalmente sustentado en el deber de información de los proveedores de servicios de comunicaciones.

Así, la Unión Internacional de Telecomunicaciones, en adelante UIT, definió la calidad del servicio como: 
"La totalidad de características de un servicio de telecomunicaciones que determinan la capacidad para satisfacer las necesidades explícitas e implícitas del usuario del servicio ${ }^{7}$ o el conjunto de características relacionadas con el rendimiento de los elementos que intervienen en la provisión de los servicios, que tienen un efecto en la provisión final de los usuarios ${ }^{\prime \prime}$.

Existe una relación directa entre el nivel de satisfacción del cliente y la calidad del servicio prestado por los proveedores del servicio de telecomunicaciones.

Según la Comisión de Regulación de Comunicaciones:

"... en la calidad del servicio se identifican dos grandes grupos (i) calidad de índole técnica, y ii) la calidad de no índole técnica, es así como para el primer grupo los parámetros son objetivos y están relacionados con los parámetros de rendimiento evaluables cuantitativamente, y para el segundo grupo los parámetros son de carácter subjetivo y están ligados con las expectativas y percepciones de los usuarios"

ii) El segundo es el de calidad de índole técnica, en otras palabras, está relacionado directamente con la prestación u operabilidad del servicio. Para esto, el ente regulador ha tenido en cuenta parámetros tales como: cobertura, accesibilidad e integridad del servicio, velocidad de transferencia de información, tasa de errores y falta de disponibilidad del servicio.

Existen, dentro del régimen de protección de usuarios, disposiciones que se pueden tipificar como parámetros de índole técnica, entre ellas, el deber de compensación del proveedor de servicios de comunicaciones y el restablecimiento del servicio una vez se haya superado la causal de suspensión del servicio.

No obstante, en relación con la calidad de índole no técnica, es decir, parámetros de índole subjetiva que están ligados directamente con la percepción del usuario, en otras palabras, la relacionada con la atención al usuario, se puede establecer una larga lista de disposiciones del régimen de protección de usuarios de servicios de comunicaciones.

Estas disposiciones tienen que ver con dos aspectos esenciales: el primero, referido a la calidad de atención de las solicitudes del usuario, y el segundo, con el deber de información que se le debe brindar a este, desde la oferta del contrato hasta su ejecución y terminación.

Dentro del referido a la calidad de atención de los usuarios de servicios de comunicaciones, se pueden clasificar las siguientes disposiciones regulatorias:

Las que tienen que ver con la calidad en la atención de las solicitudes del usuario, que son, entre otras, las siguientes:

7 Unión Internacional de Telecomunicaciones. Recomendación UIT-T-E.800, 2008, p. 3.

8 Unión Internacional de Telecomunicaicones. Recomendación UIT-T G1000, 2001, p. 2.

9 Comisión de Regulación de Comunicaciones, 2013, p.13. 
- Limitaciones o imposición de condiciones al ejercicio del derecho de libre elección del usuario ${ }^{10}$.

- Modificación unilateral de las condiciones pactadas en el contrato de las tarifas, no atención o traslados de peticiones, quejas o recursos ${ }^{11}$.

- Oposición a la solicitud de terminación del contrato por parte del usuario o cancelación de servicios adicionales ${ }^{12}$.

- No atención inmediata de las solicitudes de desbloqueo del usuario ${ }^{13}$.

Dentro de las que tienen que ver con el deber de información se pueden enunciar, principalmente, las siguientes:

- Suministro de información en el contrato sobre las condiciones de prestación del servicio contratado ${ }^{14}$ y sus modificaciones ${ }^{15}$.

- Suministro de información al usuario sobre las condiciones en que opera la cláusula de permanencia mínima ${ }^{16}$.

- Reporte negativo a bancos de datos, sin informar con 20 días de anticipación al usuario.

- Reporte a bancos de datos, a pesar de que el usuario haya pagado su obligación dentro de los 20 días de preaviso o haya negado bajo juramento la existencia de aquella.

- No actualización del reporte negativo del usuario, cuando este haya pagado dentro del mes siguiente, contado a partir del momento en que cese la mora ${ }^{17}$.

- Cobro o modificación de las tarifas, sin informar previamente al usuario ${ }^{18}$.

Información incompleta o inexacta en promociones y ofertas y empaquetamientos de servicios $^{19}$.

- Activación del servicio de roaming internacional ${ }^{20}$, entre otras.

10 Artículo 4 de la Resolución 3066 de 2011, modificado por el artículo 19 de la Resolución CRC 3530 de 2012.

11 Artículos 39, modificado por el artículo 4 de la Resolución CRC 4295 de 2013; 41, 42, 43 y 47 de la Resolución 3066 de 2011.

12 Artículos 66, modificado por el artículo 8 de la Resolución CRC 4625 de 2014, y 67 de la Resolución 3066 de 2011.

13 Artículo 105 de la Resolución 3066 de 2011, modificado por el artículo 5 de la Resolución CRC 4444 de 2014.

14 Artículo 13 de la Resolución 3066 de 2011, modificado por el artículo 5 de la Resolución CRC 4625 de 2014.

15 Artículo 15 de la Resolución 3066 de 2011.

16 Artículo 17 de la Resolución 3066 de 2011, modificado por el artículo 2 de la Resolución CRC 4444 de 2014.

17 Artículo 21 de la Resolución 3066 de 2011.

18 Artículos 27 y 28 de la Resolución 3066 de 2011.

19 Artículos 31 y 32 de la Resolución 3066 de 2011.

20 Artículo 37 de la Resolución 3066 de 2011. 
Una vez clasificadas las diferentes conductas que atañen a la calidad del servicio, en términos de la Comisión de Regulacion de Comunicaciones, de índole técnico y no técnico, se puede establecer un mapa de incentivos de cumplimiento para los proveedores de servicios de comunicaciones.

Sin embargo, previamente deberá responderse al interrogante planteado en líneas anteriores, según el cual: cel sistema sancionatorio que dispone la Ley 1341 de 2009 conmina a los proveedores de servicios de comunicaciones al cumplimiento de las normas y el respeto de los derechos de los usuarios?

\section{ANÁLISIS ECONÓMICO DEL DERECHO ADMINISTRATIVO SANCIONADOR EN TELECOMUNICACIONES}

Respecto de las principales conductas infractoras en materia de comunicaciones, a continuación se adjunta un cuadro comparativo histórico de las multas impuestas por la Superintendencia de Industria y Comercio a los proveedores de servicios móviles, desde el año 2001 hasta el primer semestre del año 2015:

GRÁFICA 1. RESPUESTA A DERECHO DE PETICIÓN DE INFORMACIÓN DEL 27 DE JULIO DE 2015. DIRECCIÓN DE PROTECCIÓN DE USUARIOS DE SERVICIOS DE COMUNICACIONES.

Valor Histórico de Multas Impuestas Dirección de Comunicaciones y Servicios Postales

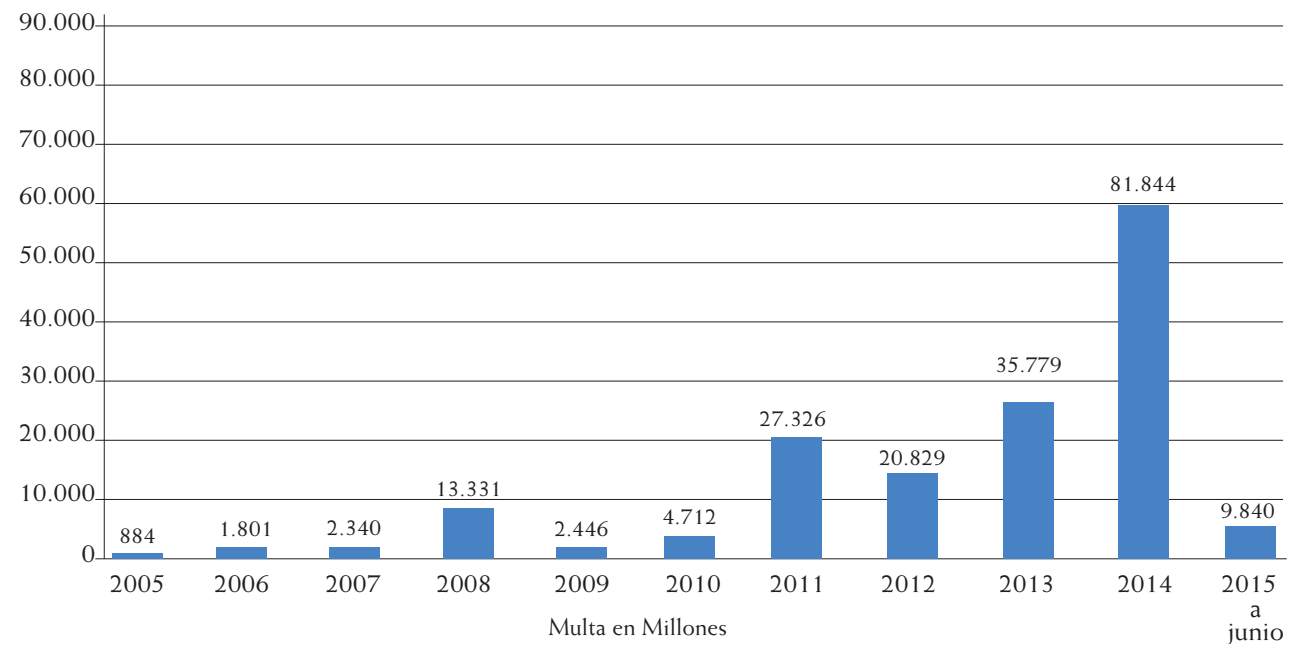

Al respecto, es preciso señalar que, mediante esta gráfica, se puede apreciar el constante aumento del valor de las multas impuestas a los operadores móviles y cómo se incrementó este durante los últimos años, como respuesta al esfuerzo de coerción del Ejecutivo para conminar al cumplimiento de las normas de protección de usuarios de los servicios de comunicaciones. 
Sin perjuicio de lo anterior, si bien se refleja la fuerte labor de inspección, vigilancia y control de la Superintendencia de Industria y Comercio en materia de comunicaciones, la conducta de infracción al Régimen de Protección de Usuarios de Servicios de Comunicaciones por parte de los proveedores no disminuye.

Esto se refleja en el inconformismo generalizado de los usuarios de servicios de comunicaciones, por la mala calidad del servicio, la cual se puede bifurcar en dos aspectos: el primero, relacionado con la calidad del servicio de atención a los usuarios, y el segundo, respecto de la calidad de prestación de los servicios de comunicaciones contratados.

Sobre este particular, la SIC ha dicho lo siguiente:

"Continúa siendo fuente de preocupación para esta Superintendencia el crecimiento de las PQR's en sede empresa, teniendo en cuenta la estricta labor de vigilancia y control que desde el año 2010 y particularmente durante el año 2011, y lo corrido de 2012, venimos adelantando, a través de múltiples acciones encaminadas a no permitir la vulneración de los derechos de los consumidores de estos servicios.

Para la Superintendencia de Industria y Comercio el número de PQR's constituye un componente esencial de la atención al usuario, cuyo incremento, merece especial vigilancia y la implementación de mecanismos especiales de inspección que coloquen freno a las fallas en la prestación del servicio por parte de los operadores" (Superintendencia de Industria y Comercio, 2012).

La cantidad de quejas por millón de usuarios a operadores de telefonía móvil en el 2012 se reflejan a continuación:

QUEJAS POR MILLÓN DE USUARIOS. OPERADORES DE TELEFONÍA MÓVIL. 2012

\begin{tabular}{|c|c|c|c|c|c|c|}
\hline \multirow{2}{*}{$\begin{array}{c}\text { PQR por millón } \\
\text { Cuarto }\end{array}$} & Comcel & Telefónica & Colombia Móvil & Uff Móvil & Une EPM & Total \\
\cline { 2 - 7 } & 446 & 224 & 366 & 880 & 150 & 2.066 \\
\hline
\end{tabular}

Fuente: elaboración Superintendencia de Industria y Comercio (Superintendencia de Industria y Comercio, 2012.

La Superintendencia de Industria y Comercio, consciente de este fenómeno, haciendo uso de sus facultades de instrucción, ha expedido diferentes circulares o instructivos, con el fin de que se cumplan planes de acción y mejoramiento, de lo cual se ha derivado, entre otras cosas, la obligación, por parte de los proveedores de servicios de comunicaciones, de reportar periódicamente a esta entidad de vigilancia y control la cantidad de peticiones, quejas y recursos recibidos por presunta vulneración a los derechos de los usuarios. No obstante, según investigaciones formales adelantadas por esta entidad, presuntamente los proveedores de servicios no estarían reportando información real en 
relación con los requerimientos de los usuarios ${ }^{21}$, lo cual fundamenta el sentimiento generalizado de inconformismo del usuario por la constante vulneración de sus derechos.

El cuestionamiento que seguiría sería el siguiente: ¿qué explica el comportamiento disidente de los proveedores de servicios de comunicaciones al cumplimiento del régimen de protección de usuarios de las comunicaciones? En este punto es necesario hacer uso del análisis económico del derecho, para intentar resolver este interrogante.

Los proveedores de servicios de comunicaciones actúan y proceden de manera racional, maximizando su riqueza:

21 "...Estarían incumpliendo la atención de quejas y peticiones de los clientes. La Superintendencia de Industria y Comercio anunció la apertura formal de una investigación contra los principales operadores móviles del país (Claro, Movistar, Tigo y Uff!) por serios indicios de incumplimiento en la atención a las quejas, peticiones y reclamos por parte de sus usuarios.

'Pareciera que las estadísticas no reflejan el estado real de las cosas', dijo el superintendente José Miguel de la Calle, quien aseguró que es muy posible que en el país se dejen de registrar 16 millones de solicitudes al mes.

Este proceso surge tras una indagación de cuatro meses al sector, en la cual se pudo establecer un volumen mensual de peticiones para el sectormóvil de 100 millones, los operadores tan sólo reportan 7.000 solicitudes al ente de control. En su análisis, la entidad pudo establecer que el 16,5\% de las solicitudes de Claro manifestaban una inconformidad, al igual que el 15,7\% de Tigo y 5,9\% de Uff! 'En el caso de Movistar, las llamadas reportadas son inaudibles', dijo De la Calle, señalando su inconformismo por este episodio. Asimismo, la SIC tiene serios indicios de que las compañías del sector habrían cometido irregularidades como la no grabación de todas las solicitudes de los usuarios, la no recepción de trámites o la no cancelación de mensajes promocionales a solicitud de sus clientes, entre otros. Esta investigación podría derivar en multas millonarias contra los implicados.

En un informe de prensa, la Dirección de Protección a Usuarios de Servicios de Comunicaciones, inició investigaciones administrativas con la formulación de los siguientes cargos a los proveedores de servicios de telefonía móvil:

- Presunta no grabación de todas las llamadas de peticiones, quejas y recursos (PQR) recibidas en la línea gratuita de atención al usuario.

- Presunta no recepción, atención, tramitación y respuesta de las peticiones, quejas y recursos (PQR) que presentan los usuarios de los proveedores de servicios a través de la línea gratuita de atención al usuario. - Presunta no remisión de la totalidad de la información exigida por la Superintendencia de Industria y Comercio.

- Presunta transgresión en la no atención personalizada de los usuarios en las oficinas físicas de atención (CAC), en un término inferior a quince (15) minutos.

- Presunto incumplimiento de la obligación de llevar un registro debidamente actualizado de las peticiones, quejas y recursos presentados por los usuarios ante las oficinas físicas de atención (CAC).

- Presunto incumplimiento de la obligación de incluir en las decisiones adoptadas las acciones adelantadas para la verificación de dichos hechos y las razones jurídicas técnicas o económicas en que se apoyan dichas decisiones.

- Presunto suministro indebido de información a los usuarios, sobre cómo opera la suspensión del servicio contratado.

- Presunta no cancelación de mensajes promocionales a pesar de la solicitud de los usuarios.

- Presunta no existencia de oficina física de atención al usuario claramente identificable para recibir, atender, tramitar y responder las peticiones, quejas y recursos que presente los usuarios" (El Espectador, 2012). 
"En efecto, como bien lo señala Posner, 'el concepto del hombre como un ser racional que tratará de aumentar al máximo su interés propio implica que la gente responde a los incentivos; que si cambian las circunstancias de una persona en forma tal que podría aumentar sus satisfacciones alterando sus comportamientos, lo hará así. Estos incentivos al comportamiento del hombre racional pueden ser inducidos por las normas jurídicas.

Cuando un agente respeta o quebranta una norma recibe una recompensa o incurre en un costo (precio) derivado de dicho comportamiento. Por ello se afirma que las leyes crean precios implícitos para tipos diferentes de conductas" ${ }^{\prime \prime 2}$.

Lo anterior, con el fin de explicar la conducta de los proveedores de servicios de comunicaciones, puesto que dentro de las diferentes estrategias de juego que tienen los proveedores, actuando como un agente racional desde la perspectiva de la Escuela Clásica, el jugador dominante ${ }^{23}$ se manifiesta en su preferencia por el incumplimiento de la Regulación de Protección de los Derechos de los Usuarios de los Servicios de Comunicaciones, dado que el costo (las sanciones pecuniarias) nunca será mayor al beneficio (infracción).

Para POSNER:

"... Lo que debe maximizarse, al menos como lo entienden hoy la mayoría de los utilitaristas, no es un particular estado psicológico de éxtasis, euforia o lo que fuere, sino el concepto más amplio posible de satisfacción. La felicidad, la utilidad, se maximizan cuando las personas (o las criaturas) son capaces de satisfacer sus preferencias, cualesquiera que éstas sean, hasta la máxima extensión posible"24.

En este sentido, se puede decir que los proveedores de servicios de telefonía móvil son maximizadores de riqueza. RICHARD POSNER define la riqueza como:

“... el valor en dólares o el equivalente en dólares de cualquier cosa en una sociedad'. La riqueza, así entendida, se mide a partir de lo que un individuo está dispuesto a pagar por algo o, si ya lo posee, por lo que está dispuesto a recibir para desprenderse de ello"25.

Los proveedores de servicios actúan racionalmente, en términos económicos, por lo que responden únicamente a incentivos; es ahí donde el Estado, en su papel interventor y regulador, debe diseñar políticas que, en efecto, incentiven al operador móvil a satisfacer las necesidades inmediatas de los usuarios de telefonía móvil.

22 Amador Cabra, L. E. y Grisales, R. La Ley 142 de 1994 desde la perspectiva del análisis económico del derecho, en Contexto, 2011, n. ${ }^{\circ} 29$, p. 14.

23 Hurwicz, L. Op. cit., pp. 577-585.

24 MartíneZ, C. Maximización de la riqueza y asignación de derechos en Richard Posner (Wealth maximization and allocation of rights according to Richard Posner), en Persona y Derecho, 2009, n. ${ }^{\circ}$ 60, p. 332.

25 MarTíneZ. Op. cit., pp. 333 y 334. 
"El concepto del hombre como ser racional que tratará de aumentar al máximo su interés propio implica que la gente responde a incentivos que si cambian las circunstancias de una persona en forma tal que podrá aumentar sus satisfacciones alterando su comportamiento, lo hará asî́26.

Teniendo en cuenta lo anterior, el análisis debe centrarse en la conminación utilizada en la ley para lograr el cumplimiento de esta, la cual tiende a no ser eficiente. Es por esto que debemos tener en cuenta que el fin último de cada norma, que permea el ordenamiento jurídico, es lograr el cumplimiento de lo allí señalado.

Sin embargo, se le ha dado prioridad a la imposición de sanciones como la única herramienta que permite cumplir con la norma, cuando lo importante es el cumplimiento del fin señalado en la norma. Las sanciones son solo un mecanismo que permite a la administración ejercer un poder coercitivo sobre aquellos destinatarios de la norma que no la están cumpliendo. Es por eso que, tal vez, el equívoco está dado en que el Estado aporta más autoridad y menos poder de negociación de los particulares.

Si lo analizamos desde la óptica del análisis económico del derecho, las multas, en palabras de Posner, se pueden explicar de la siguiente manera: para el delincuente, el castigo es el precio que cobra la sociedad por la ofensa criminal ${ }^{27}$. El economista pronostica que un aumento de la severidad del castigo o de la probabilidad de su imposición elevará el precio del delito y, por lo tanto, reducirá su incidencia. El delincuente se sentirá estimulado para realizar otra actividad, en lugar del delito ${ }^{28}$.

Asimismo, Robert COOTER y ThOMAS Ulen equiparan las sanciones a los precios:

"Para los economistas, las sanciones son como los precios y, supuestamente, los individuos responden a esas sanciones de una manera muy similar como responden a los precios. Los individuos, responden ante las sanciones legales más severas realizando menos la actividad sancionada. La economía cuenta con teorías matemáticamente precisas (la teoría de precios y la teoría de juegos) y métodos empíricamente razonables (la estadística y la economía) para analizar el efecto de los precios en el comportamiento"29.

En este sentido lo afirma el autor ANTONIO BERISTAN, en su libro Eutanasia, dignidad y muerte, al expresar:

"Coffe y otros critican la eficacia de las sanciones pecuniarias (especialmente cuando se imponen como sanciones administrativas, sin reproche a condena penal) porque pueden y suelen ser desproporcionadas a las ganancias obtenidas y porque la empresa o la sociedad fácilmente las cubre computándolas en el capítulo de costos en los precios de venta"30. 
De ahí que podamos decir que el empresario, cuando actua de forma racional, buscando maximizar sus utilidades, y encuentra en la infracción a la norma una fuente de reducción de costos de producción o prestación de servicios, siendo más barato para él, por ejemplo, hacer provisiones contables o contratar más seguros con el fin de pagar la multa que posteriormente le será impuesta, lo hará, dado que es más "barato" incumplir la norma que cumplirla.

Con el fin de ejemplificar lo anteriormente descrito, dar un soporte de resultados y medir la desproporción entre las ganancias obtenidas y el valor de las multas impuestas, se traerán a colación los siguientes datos:

VALOR DE LAS MULTAS IMPUESTAS A PROVEEDORES DE SERVICIOS MÓVILES, AÑO 2013

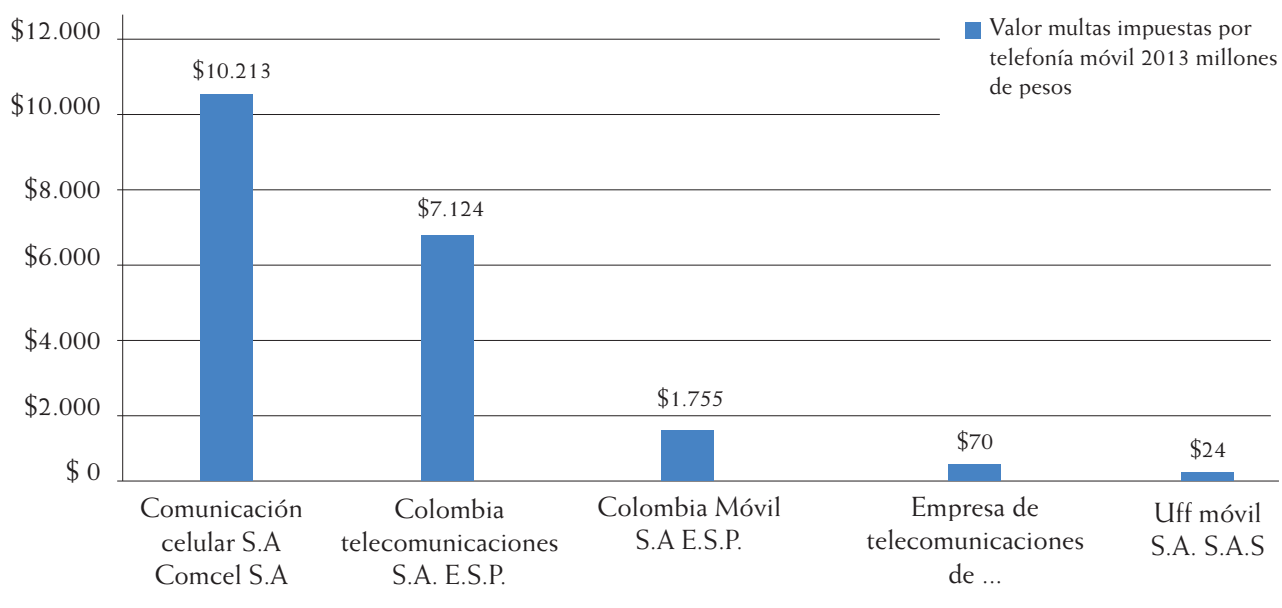

VALOR MULTAS IMPUESTAS A PROVEEDORES DE SERVICIOS MÓVILES, AÑO 2014

\begin{tabular}{|c|c|c|c|c|c|c|c|c|c|}
\hline$\$ 20.000$ & $\$ 19.766$ & \multicolumn{5}{|c|}{$\$ 17.071$} & \multicolumn{3}{|c|}{$\begin{array}{l}\text { Valor multas impuestas sector } \\
\text { telefonía móvil } 2014 \text { millones } \\
\text { de pesos }\end{array}$} \\
\hline$\$ 10.000$ & & & $\$ 10.599$ & $\$ 9.957$ & & & & & \\
\hline$\$ 5.000$ & & & & & & & & & \\
\hline$\$ 0$ & & & & & $\$ 1.997$ & $\$ 1.606$ & $\$ 556$ & $\$ 378$ & $\$ 319$ \\
\hline & 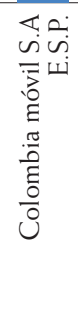 & 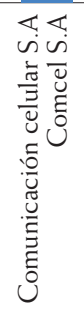 & 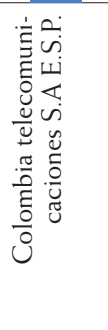 & 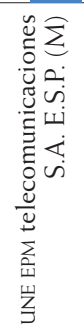 & 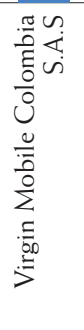 & 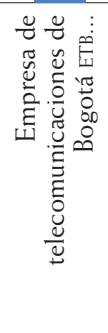 & 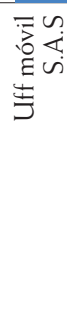 & 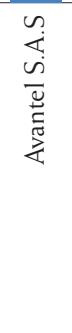 & 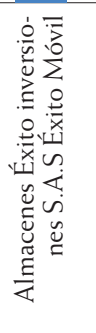 \\
\hline
\end{tabular}


Extrayendo el caso puntual de la sociedad Comunicación Celular S.A. Comcel S.A., es preciso indicar que 1.314 millones de dólares (Portafolio, 2013) corresponden a la utilidad neta de esta compañía durante el $2012^{[31]}$.

Es decir que la diferencia entre la utilidad recibida y las multas impuestas por la Superintendencia de Industria y Comercio a esta empresa es de 1.000 millones a 4 millones de dólares, aproximadamente.

En el 2013, la utilidad neta fue de \$1.481.316.094.000 (Comcel S.A., 2015), que equivalían, al 31 de diciembre de $2013^{[32]}$, a 768.784 .010 dólares, mientras que el monto de multas impuestas en el 2013 fue de \$10.211.986.500, que equivalían, a esa fecha, a 5.299.890 dólares, una relación de 5,2 millones de dólares (multas) a 768,7 millones de dólares (utilidades).

Ahora bien, en el 2014, la utilidad neta de Comcel S.A. fue de $\$ 2.047 .812 .642 .000$ (Comcel S.A., 2015), que equivalían, a 31 de diciembre de $2014^{[33]}$, a 855.944.359 dólares, mientras que el monto de multas impuestas fue de $\$ 17.071 .108 .000$, que equivalían, a esa fecha, a 7.135.379 dólares, una relación de 7,1 millones de dólares (multas) a 856 millones de dólares (utilidades).

Teniendo en cuenta que el promedio del valor de las multas impuestas por la Superintendencia de Industria y Comercio, Dirección de Protección de Usuarios de Servicios de Comunicaciones, en los años 2012 a 2014, haciendo un ponderado, no llega ni al 0.36\% del valor de las utilidades netas de Claro, aumentan las probabilidades de que tengan presupuestadas en un su estado de caja las multas que, pronostican, impondrá la SIC por el incumplimiento de las normas de protección de usuarios de comunicaciones, lo cual hace que se generen incentivos negativos, en tanto y cuanto la sanción no está cumpliendo su función de conminar al empresario a portarse bien, sino, todo lo contrario, ayuda a la obtención del provecho económico a través del incumplimiento de sus obligaciones.

Se puede decir que los proveedores de servicios podrían, racionalmente, prever el monto de las sanciones, y estimar el costo anualmente:

"Supongamos que un fabricante sabe que su producto dañará a veces a los consumidores. ¿En qué medida mejorará la seguridad del producto? La respuesta depende de dos costos: primero,

31 Portafolio.co "Carlos Slim guardará utilidad de Comcel en Colombia (marzo 5 de 2013 - 9:41 am)

La junta directiva de Comcel, controlada por América Móvil, del magnate Carlos Slim, enviará a la reserva legal y de futuros repartos $\$ 2,4$ billones.

Ese monto, equivalente en dólares a 1.314 millones, corresponde a la utilidad neta de la compañía durante el 2012, que solo fue superada por Ecopetrol y que en el año anterior tuvo beneficios netos cercanos a 15 billones de pesos. La asamblea de la celular se realizará el 27 de marzo de este año en Bogotá.

Durante el 2012, los ingresos de Comcel (Claro) sumaron 7,7 billones de pesos, con un incremento de 9,8 por ciento respecto del 2011, mientras que la utilidad neta de Comcel creció 29,8 por ciento respecto del 2011.

El mundo tiene 1.426 multimillonarios, según reveló este lunes la revista 'Forbes'. El mexicano Slim lidera la lista con una fortuna de 73.000 millones".

32 Tasa Representativa del Mercado -TRM- del 31 de diciembre de 2013. www.banrep.gov.co

33 Tasa Representativa del Mercado -TRM- del 31 de diciembre de 2014. www.banrep.gov.co 
el costo real de la seguridad, el que a su vez depende de ciertas características del diseño y la manufactura, segundo, el 'precio implícito' de los perjuicios causados a los consumidores que se debe pagar mediante la responsabilidad legal del fabricante. La responsabilidad es una sanción por lesionar a otros. Para estimar el precio implícito el productor necesitará el auxilio de abogados. Luego de obtener la información necesaria, el productor comparará el costo de la seguridad con el precio implícito de los accidentes. Para maximizar los beneficios, el productor ajustará la seguridad hasta que el costo real de la seguridad adicional se iguale al precio implícito de los accidentes ocasionales" ${ }^{\prime 34}$.

Sin importar la cantidad de sanciones o que el valor de estas haya aumentado significativamente, el proveedor de servicios mantendrá su comportamiento racional y preferirá, dentro de sus estrategias comerciales, darle prelación a la inversión en el esquema de ventas y marketing, antes que a la inversión en el mejoramiento de la calidad del servicio y la atención de este.

Según estadísticas de la Superintendencia de Industria y Comercio, año 2012 ${ }^{35}$, de acuerdo con los reportes de los operadores, las quejas más frecuentes son las relacionadas con los siguientes aspectos:

- Facturación indebida

- Cobro indebido de servicios

- Deficiencia en la calidad y prestación del servicio

- Negación de llamadas de fijo a celular o trunking

- Reporte en centrales de riesgo

- No abono oportuno

Se debe tener en consideración que, no obstante la entidad de control opte por graduar la sanción teniendo en cuenta los criterios dados por la ley e imponga la multa límite al proveedor de servicios, este podría seguir teniendo un margen considerable de utilidades.

Al respecto, en esta materia, tal y como se mencionó anteriormente, el legislador, mediante la Ley 1753 de 2015, que modificó el artículo 65 de la Ley 1341 de 2009, en su artículo 44, dispusó:

"... 2. Multa hasta por el equivalente a dos mil (2.000) salarios mínimos legales mensuales para personas naturales.

3. Multa hasta por el equivalente a quince mil (15.000) salarios mínimos legales mensuales para personas jurídicas...". 
En este sentido, teniendo en cuenta los criterios de imposición de la sanción, entre ellos la gravedad de la falta y la proporcionalidad entre la falta y la sanción, imponer multas de 15.000 salarios mínimos legales mensuales vigentes para una persona jurídica debido a una infracción relacionada con el marco referido a la calidad de atención de los usuarios de servicios no sería proporcional, salvo que exista una acumulación extensiva de casos similares.

Vale la pena resaltar que dentro de ese marco referido a la calidad de atención de los usuarios, tal y como se describió anteriormente, se encuentran normas relacionadas con el deber de información a los usuarios, facturación indebida o reporte negativo a centrales de riesgo, entre otras.

Ahora bien, si se hiciera el ánalisis de una multa de 15.000 salarios mínimos mensuales vigentes versus la utilidad de Claro en el 2014, por ejemplo, el resultado sería de 3.1 millones de dólares (multa) versus 668 millones de dólares (sanción).

Es necesario señalar que al momento de imponer una sanción, hay dos aspectos esenciales para tener en cuenta en la graduación de esta: en primer lugar, la sanción debe contener un óptimo en el cual se encuentren incluidos el beneficio reportado al infractor con la infracción de la norma y el costo que implica para la administración la detección e imposición de la sanción.

Para POSNER:

"la mejor combinación de probabilidad y severidad del castigo para imponer al delincuente, cuando el castigo es una multa, puede ser la siguiente: 'un costo esperado del castigo de 1.000 dólares puede imponerse combinando una multa de 1.000 dólares con una probabilidad de aprehensión y condena de 1, una multa de 10.000 dólares con una probabilidad de .1, una multa de un millón de dólares con una probabilidad de .001, etc. Si los costos del cobro de las multas se suponen iguales a cero cualquiera que sea el monto de la multa, la combinación más eficiente es una probabilidad arbitrariamente cercana a cero y una multa arbitrariamente cercana al infinito. Porque mientras que los costos de la aprehensión y la condena de los delincuentes aumentan con la probabilidad de la aprehensión -mayores probabilidades implican más policías, fiscales, jueces, abogados, defensores, etc., que cuando la probabilidad de la aprehensión es muy baja- los costos del cobro de las multas son por hipótesis nulos independientemente de su monto. Así pues, todo aumento del monto de la multa no cuesta nada, mientras que toda disminución correspondiente de la probabilidad de aprehensión y condena, destinada a contrarrestar el aumento de la multa y mantener así un costo constante del castigo esperado, disminuye los costos del cumplimiento forzoso, hasta el punto del desvanecimiento si la probabilidad de la aprehensión y la condena se reduce a un nivel arbitrariamente cercano a cero" ${ }^{\prime \prime}$.

Así las cosas, siempre debe ser mayor la sanción que el beneficio reportado con la infracción, dado que si la sanción es más barata que la ganancia reportada con la infracción, 
el infractor siempre preferirá infringir la norma y pagar la sanción, toda vez que esa operación arroja un resultado positivo.

Dicho en otras palabras, tendrá derecho el acreedor (en este caso la SIC) a que se le repare el daño (o imponer una sanción) en una cantidad equivalente o superior a los costos del cumplimiento; así el derecho internaliza todos los costos de incumplir a tráves de la responsabilidad civil -o en este caso, del derecho administrativo sancionador- ${ }^{37}$.

El segundo aspecto esencial que debe contener la sanción es, a mediano plazo, la disuasión de la comisión de la infracción, dado que si las sanciones impuestas son óptimas y, en consecuencia, es más barato respetar la ley que infringirla, el número de infracciones a la ley disminuirá.

Asimismo, debe respetarse el criterio de gravedad y proporcionalidad entre las faltas y las sanciones, puesto que si se castigan todas las conductas con la misma severidad, "se elimina la disuasión marginal, el incentivo para sustituir delitos más graves por otros menos graves" 38 .

No obstante que las sanciones propenden a ser disuasorias, se debe tener en cuenta la capacidad de pago del infractor; así pues, no se sancionará de la misma forma a una persona natural o empresa sin ánimo de lucro, que a una persona jurídica.

Por lo tanto, es preciso preguntarse si la regulación vigente en materia de protección de los derechos de usuarios de servicios de comunicaciones y sus herramientas de coerción son eficaces, es decir, si cumplen el acometido para el cual fueron creadas, en este caso, el Régimen de Protección de Usuarios de Servicios de Comunicaciones expedido por la Comisión de Regulación de Comunicaciones.

Como respuesta al cuestionamiento planteado, quedó demostrado que el ejercicio de la facultad sancionatoria de la Superintendencia, en los términos dados por la ley, no es suficiente para conminar a los destinatarios obligados del régimen a cumplir la regulación.

En este sentido, lo que se busca es que el usuario sea el que defina el mercado, en ejercicio de su poder de elección; pero con la imposición de sanciones pecuniarias no siempre se logra el fin de la intervencion estatal en la economía, que en materia de regulación de comunicaciones, es garantizar el respeto por el derecho de los usuarios de servicios de comunicaciones.

Así, es muy díficil para quien ejerce el control, garantizar que las sanciones pecuniarias sean disuasorias, es decir, determinar que el monto de la sanción sea más alto que el beneficio obtenido por el infractor; de otro lado, porque no existe igual número de castigos (sanciones) frente al número de infracciones cometidas.

Para COOTER y Ulen, "[e]l castigo de los delincuentes es probabilístico. Es posible que el delincuente no sea descubierto o aprebendido, o que sea aprebendido pero no condenado. Una persona que toma decisiones racionales toma en cuenta la probabilidad del castigo cuando considera cometer cualquier delito,

37 BARCIA LEHMAN, R. Los Efectos de las obligaciones desde la perspectiva del análisis económico del derecho, en Cuadernos de Análisis Jurídicos. Colección de Derecho Privado I. Temas de Responsabilidad Civil, p. 142. 
incluido el abuso de confianza. Podemos decir que el abusador racional calcula un valor esperado del delito descontando la cantidad que espera ganar por la incertidumbre del castigo"39.

Para lograr esto, debe existir un cambio en la forma como se sanciona, o mejor, en la forma como se debe imponer una sanción, tanto del monto que se va a imponer como de los criterios de graducación. Dicho de otra forma, "los individuos responden a los incentivos", entonces, como las personas "toman decisiones comparando los costes y los beneficios, su conducta puede cambiar cuando se cambian los costes y los beneficios" (MANKIW, 2002, p. 5), con lo cual lo que debe hacer el policymaker es crear incentivos para que a los empresarios les sea más rentable comportarse bien que comportarse mal. Mirémoslo de la siguiente manera:

Lo primero acerca de lo cual debe haber claridad consiste en el sistema de responsabilidad bajo el cual la administración, en este caso la SIC, está imponiendo las sanciones a las que hubiere lugar. En este punto, compartimos lo señalado por autores como OssA, el cual sostiene que un régimen de responsabilidad objetiva para este tipo de asuntos genera incentivos negativos al empresario, en tanto y cuanto se tiende a eliminar los incentivos de prevenir la conducta, contrario a lo que ocurre bajo un sistema de responsabilidad subjetiva en el cual el incentivo es a prestar un servicio o producir un bien de excelente calidad, dada la necesidad de culpabilidad que debe acompañar el "mal" comportamiento, para responder ${ }^{40}$.

Sin embargo, de acuerdo a lo anterior y citando otros autores como ACCIARRI y POLINSKY, también podemos sostener que tanto en sistemas de responsabilidad subjetiva como objetiva, los potenciales transgresores de la norma elegirán siempre el nivel óptimo de precaución, que es lo mismo que decir que "el sistema conduce a resultados eficientes" 41 , y que en escenarios propios como el del derecho del consumo, es importante intentar reducir al máximo la asimetría de información, porque solo cuando hay neutralidad respecto del riesgo y los consumidores poseen información perfecta -o por lo menos se acercan a ella respecto de las empresas y sus productos-, podríamos decir que cualquier sistema de responsabilidad (objetivo o subjetivo) sería eficiente ${ }^{42}$. Sobre este particular volveremos más adelante, pues es esencia base de la propuesta que incluiremos al final para solucionar la problemática aquí trazada.

\section{UNA PROPUESTA DE SOLUCIÓN}

Una vez señalada la problemática y visto que la función preventiva de la norma no se cumple, tal vez, o por lo menos así lo creemos nosotros, por el nivel de sanción y la

40 Ossa Bocanegra, C. Análisis económico de las sanciones administrativas en el derecho de la competencia y del consumo, en Revista de Derecho del Estado, 2015, n. ${ }^{\circ} 35$, pp. 168 y ss.

41 ACCIARri, H. A. El análisis económico del derecho de daños. Una aproximación general, en BERNAL PULIDO, C. y FABRA ZAMORA, J. La filosofía de la responsabilidad civil. Estudios sobre los fundamentos filosófico-jurídicos de la responsabilidad civil extracontractual. Bogotá D.C.: Universidad Externado de Colombia, 2013, p. 446. POLINSKY, A. Introducción al análisis económico del derecho. Barcelona: Ariel S.A., 1985, p. 115. 
forma como se aplica esta, pasaremos a proponer una posible solución al problema, la cual se basa en lo siguiente:

Debemos procurar por la creación de una política pública donde la intervención gubernamental se revestirá, en términos de RiCHARD H. THALER y CaSs R. Sustein, en un paternalismo libertario:

"El paternalismo libertario es un tipo de paternalismo relativamente débil y blando, y que no supone una intromisión porque las opciones no se bloquean ni se eliminan, ni se gravan de forma significativa. Si alguien quiere fumar, comer muchos caramelos, suscribir un seguro médico, poco ventajoso o no ahorrar para la jubilación, los paternalistas libertarios no le obligaremos a que actúe de otra forma (ni siquiera le pondremos las cosas difíciles). Sin embargo, el enfoque que recomendamos se considera paternalista porque los arquitectos de las decisiones públicos y privados no se limitan a intentar identificar o poner en práctica las decisiones que se esperan de las personas. Más bien, intentan orientarlas en direcciones que mejorarían sus vidas" ${ }^{\prime \prime 3}$.

Aquí cabe mencionar que si bien la regulación vigente establece, dentro del deber de información, como obligación de los proveedores de servicios: i) la publicación de los índices de calidad en la atención al cliente en las oficinas físicas y virtuales, y ii) la publicación actualizada (mensual) de los índices de calidad en la atención al cliente en las oficinas físicas y virtuales, los usuarios de servicios de comunicaciones no cuentan con herramientas útiles que les permitan ejercer su derecho de elección del respectivo proveedor de manera informada, en ejercicio de un consumo responsable y sin racionalidad limitada, y no puede ser de otra forma, puesto que los proveedores de servicios no informan a los usuarios de estas calidades de forma adecuada, es decir, de manera clara y de fácil entendimiento.

En relación con este aspecto, es necesario traer a colación la visión de la Nueva Economía Institucional, la cual le da especial relevancia a los costos de transacción en la búsqueda de la información relevante para los consumidores. Así lo manifiesta, PINZÓN CAMARGO, al señalar lo siguiente:

"... En primera instancia, los costos de transacción implican limitaciones para los agentes que se encuentran interesados en llevar a cabo una transacción, ya que suponen el análisis obligatorio de información suficiente y relevante para desarrollar una negociación, de forma tal, que se garantice igualdad de condiciones entre las partes involucradas.

No obstante, el acceso a dicha información se verá limitado por los costos de acceso, así los agentes tendrán que tener en cuenta sus restricciones presupuestales para acceder a un nivel determinado de información, por tanto, es posible que los participantes no puedan acceder a la información de manera plena y suficiente, implicando a cabo una transacción que no

43 Thaler, Richard H. y Sunstein, Cass R. Un pequeño empujón (Nudge). Mexico, D.F.: Taurus, 2009, p. 29. 
necesariamente sea la más eficiente, en cuanto no es posible sopesar los costos de oportunidad que se dejan de lado, por no tener acceso a datos relacionados con estos" ${ }^{\prime \prime}$.

La restricción de acceso a la información esencial para los usuarios de servicios de comunicaciones se puede quebrantar al generarse herramientas de información que le permitan fácilmente identificar las calidades de prestación de los servicios de los pocos, pero diferentes, proveedores de servicios de comunicaciones.

La propuesta que se plantea, y que tiene como objeto reducir la asimetría de información que lleva a los usuarios de servicios de comunicaciones a efectuar una selección adversa de su operador móvil, consiste en utilizar algunas de las herramientas de información señaladas en las directrices que se han dado en el campo de consumo sostenible en el ámbito de las organizaciones internacionales.

La asimetría de la información debe reducirse, de manera tal que los costos de transacción para que los usuarios accedan a aquella sean nulos. De esta forma, deben ser "nudges" 45 ubicados en la etapa precontractual de la relación comercial entre usuarios y proveedores de servicios de comunicaciones:

"Los que eligen son seres humanos, por lo que los diseñadores deberían hacer las cosas tan fáciles como fuera posible: enviar recordatorios y después intentar minimizar los costos impuestos a aquellos que, a pesar de sus esfuerzos, no prestan atención"46.

Para lograr esto, lo que proponemos es que, en primer lugar, se cree un sistema de calificación para graduar la calidad de los servicios de los proveedores de servicios de comunicaciones, teniendo en cuenta sus principales intereses a la hora de contratar sus servicios.

Ello, puesto que, hoy, los proveedores de telefonía móvil ofertan y publicitan elementos de atracción para los usuarios, tales como: tecnología ( $2 \mathrm{G}, 3 \mathrm{G}$ y 4G), velocidad en datos, mayores aplicaciones y servicios.

ILUSTRACIÓN 3. ENTORNO SECTORIAL TIC NACIONAL

\begin{tabular}{|l|c|c|}
\hline \multicolumn{1}{|c|}{ Aspecto } & Años Previos & Hoy \\
\hline Cantidad de operadores & 3 & 7 \\
\hline Tegnología en el mercado & $2 \mathrm{G}$ y $3 \mathrm{G}$ & $2 \mathrm{G}, 3 \mathrm{G}$ y $4 \mathrm{G}$ \\
\hline Espectro IMT asignado & $140 \mathrm{MHz}$ & Datos: crecimiento acelerado. \\
\hline
\end{tabular}

44 Pinzón Camargo, M. Aproximaciones al análisis económico del derecho, 2010, p. 76.

45 "Un nudge, tal y como empleamos el término, es cualquier aspecto de la arquitectura de las decisiones que modifica la conducta de las personas de una manera predecible sin prohibir ninguna opción ni cambiar de forma significativa sus incentivos económicos. Para que se pueda considerar como nudge, debe ser barato y fácil de evitar. Los nudge no son órdenes. Colocar la fruta de forma bien visible es un nudge. Prohibir la comida basura no lo es" (SUSTEIN, 2009, p. 20).

46 Thaler y Sunstein. Op. cit., p. 28. 


\begin{tabular}{|l|c|c|}
\hline \multicolumn{1}{|c|}{ Aspecto } & Años Previos & Hoy \\
\hline Servicios y consumo & $\begin{array}{c}\text { Voz: crecimiento desacelerado } \\
\text { Datos móviles: iniciando } \\
\text { aceleración }\end{array}$ & $\begin{array}{c}\text { Mayores velocidades, nuevas } \\
\text { aplicaciones y masificación de } \\
\text { servicios }\end{array}$ \\
\hline Bandas IMT asignadas & 850 y $1900 \mathrm{MHz}$ & $\begin{array}{c}850, \text { AWS, } 1900 \text { y } 2500 \mathrm{MHz} \\
\text { Próximas: } 700 \text { y } 900 \mathrm{MHz}\end{array}$ \\
\hline TRM promedio & $\begin{array}{c}\text { Menor a } \$ 1900^{*} \\
(*) 2010 \text { a } 2013\end{array}$ & $\begin{array}{c}\text { Mayor a } \$ 2400 \text { Proyección: } \\
\text { mayor devaluación }\end{array}$ \\
\hline
\end{tabular}

Fuente: Análisis ANE (Agencia Nacional del Espectro, 2015).

No obstante, a los usuarios de telefonía móvil no solo les deben interesar dichos elementos, sino que, además, estos sean acordes a la realidad y que sus peticiones se resuelvan con prontitud y de fondo. Para ello, los usuarios deben contar con herramientas de información sencillas, relacionadas con estos aspectos, y que además permitan calificar a los prestadores del servicio bajo un sistema basado en antecedentes reputacionales, donde los procesos tradicionales de sanción sean cambiados por por sanciones sociales $\mathrm{y}$ reputacionales.

Esto hace que los intereses de todas las partes se maximicen, si se mantienen en registros públicos; entonces, en estos casos, se generan fuertes incentivos para mantener altos niveles de reputación de lado y lado, permitiendo a futuros clientes tomar una decisión acorde a sus preferencias, o incluso a los que ya son usuarios del servicio, poder tomar una decisión anterior al cambio de operador, con base en las preferencias. Este tipo de sistemas pueden ayudar, incluso, a reducir los grupos de interés, toda vez que una de las funciones de los grupos de interés es llevar información entre los ciudadanos y quienes toman las decisiones, lo cual no sería necesario, dada la reducción de asimetrías de información entre los prestadores del servicio y los usuarios ${ }^{47}$.

Esto lleva, como ya lo señalamos antes, a que se genere un cambio completo en el análisis de los costes y los beneficios que tiene el potencial infractor a la norma; por ende, dado que los individuos responden a incentivos, y siendo el servicio prestado al usuario final el que determina su nivel de utilidad, todos los incentivos están dados para que el prestador del servicio intente mantener o aumentar su demanda, es decir, comportarse "bien" con el usuario final, para que su beneficio pueda ir en aumento.

47 La calificación, como propuesta, estaría dada mediante puntajes dados por el regulador basados en informes presentados por la entidad de vigilancia y control, Superintendencia de Industria y Comercio, soportados en dos variables: la cantidad y el valor de las multas en firme impuestas por la entidad de vigilancia, supervisión y control por las diferentes infracciones cometidas, divididos en las dos variables descritas anteriormente: disposiciones de índole técnico (prestación y operatividad del servicio) y no técnico (calidad en la atención e información), siempre teniendo en cuenta las quejas más frecuentes presentadas por los usuarios en servicios de telefonía móvil. 
De esta manera, podrán los usuarios realizar una elección racional, responsable e informada entre los diferentes oferentes del mercado, donde no solo el precio tenga un factor determinante ${ }^{48}$.

\subsection{Caso Reino Unido: competencia por comparación de indicadores}

La entidad que regula las empresas de distribución de agua y alcantarillado en el Reino Unido, Inglaterra y Gales, es la Office of Water Regulation, OFWAT. Su metodología se basa en la consolidación de datos e información de diferentes aspectos, tanto financieros como de operación de dichas empresas; asimismo, utiliza metódos de análisis de la información, la cuál es conocida tanto por la autoridad como por las empresas competidoras. Dentro de la información que recauda esta autoridad, se encuentra la de recopilación de los planes de inversiones. El objetivo de la autoridad es aumentar los niveles de eficiencia de dichas empresas, a tráves de la fijación de indicadores como la intervención en la fijación de precios, teniendo como soporte la reducción de costos operativos de la compañía, exigiendo la implementacion de sistemas novedosos de reducción de estos.

Dentro de los diferentes indicadores, se encuentran tanto la calidad en la prestación del servicio como los niveles de atención a los clientes, entre muchos otros ${ }^{49}$.

La OFWAT determinó unos "indicadores clave", los cuales deben ser publicados por cada compañía anualmente. Estos indicadores proporcionan a los reguladores, inversores y usuarios un panorama general de rendimiento de la empresa.

Dentro de los principales indicadores se encuentran:

- El nivel de satisfacción de los clientes con el servicio de la empresa, y cómo la empresa se ocupa de aquel.

- Número de incidentes de inundaciones de alcantarillado.

48 Como dato para tener en cuenta, hoy existen más de siete oferentes de estos servicios en Colombia, entre ellos: Colombia Móvil S.A. E.S.P. - TIGO, Comunicación Celular S.A. Comcel S.A. -CLARO-, Colombia Telecomunicaciones S.A. E.S.P. -MOVISTAR-, UNE EPM Telecomunicaciones, Virgin Mobile Colombia S.A.S, Empresa de Telecomunicaciones de Bogotá ETB S.A. E.S.P., UFF Móvil S.A.S., Avantel S.A.S. y Almacenes Éxito Inversiones S.A. ÉXITO MÓVIL.

49 Dentro de la regulación de los servicios públicos, el Reino Unido ha dado gran importancia a la calidad de la prestación del servicio. Es así como en la prestación del servicio de acueducto, la Office of Water Services K - OFWAT realiza mediciones anuales sobre la prestación del servicio, otorgándoles un puntaje a los proveedores sobre el Overall Performance Assessment (OPA) - que refleja la calidad de los servicios prestados, para lo cual tiene en cuenta los siguientes ítems: abastecimiento de agua (presión de agua, las interrupciones para el suministro, la prohibición de manguera y calidad del agua potable); servicio de alcantarillado (drenaje incidentes inundaciones y el riesgo de inundaciones); servicio al cliente (quejas por escrito, los contactos de facturación, lectura de medidores, atención telefónica, acceso telefónico, servicios a ancianos y discapacitados clientes, el suministro de las políticas de reparación de tuberías, la deuda y las políticas de ingresos, tramitación de las reclamaciones, indemnizaciones y suministro de información a clientes), impacto ambiental (fugas, las obras de tratamiento de aguas residuales, la contaminación, incidentes de agua y actividades de saneamiento y disposición de lodos) (Comisión de Regulación de Comunicaciones, 2013, pp.19-20). 
- Interrupciones en el servicio de agua.

- La tendencia histórica en la capacidad de servicio a los clientes, medida por movimientos en el desempeño del servicio.

- Total de fugas. Mide la suma de las pérdidas de distribución de suministro.

- Incidentes de contaminación.

Si bien en el Reino Unido la intervención del regulador en el despempeño empresarial de las empresas de agua y drenaje es tan drástico que incluso se pueden llegar a definir tarifas adecuadas, en esta propuesta lo que se pretende, además de enfatizar en indicadores de calidad direccionados a la calidad de la atención a los usuarios de telefonía móvil, es crear herramientas de información de fácil acceso y entendimiento para el usuario cómun.

Estas herramientas de información sobre la calidad de un servicio no pueden traducirse en la fijación de indicadores de calidad, sino que debe crearse un sistema de calificación de calidad mediante el cual el usuario pueda identificar qué servicio de telefonía móvil, en aspectos de atención al cliente, es sobresaliente, satisfactorio o insatisfactorio, así como en aspectos de cobertura y prestación técnica del servicio, clasificándolo con base en factores geográficos en relación con la prestación del servicio y el despliegue de la infraestructura de comunicaciones.

Dichas calificaciones de nivel de servicio deben ser dadas por la autoridad de control y vigilancia, basadas en la recopilación de datos e información relevante en estos aspectos.

Así pues, una vez calificados los diferentes proveedores de servicios de telefonía móvil, es necesario divulgar dicha información a los usuarios, no solo a través de los medios informativos de la autoridad de vigilancia y control en los diferentes medios de información que ha establecido el regulador para brindar información a los usuarios de telefonía móvil, tales como las oficinas físicas y virtuales de atención, sino a través del contrato.

\section{CONCLUSIONES}

La calidad del servicio de comunicaciones de telefonía móvil y sus servicios conexos, tales como la transmisión de datos, no es óptima en Colombia. Son diversos los factores que pueden verse involucrados en la calidad del servicio, entre ellos, se encuentran:

La deficiencia de antenas de telefonía móvil que existe en el país; ahora más, cuando existe temor en la comunidad por el riesgo que pueden ocasionar a la salud los campos radioeléctricos que emiten las antenas de telefonía móvil. Ello ha producido que tanto entidades gubernamentales, tales como alcaldías, sumados a los jueces de la República, emitan decisiones que prohíben la instalación de estas en zonas urbanas. Esto genera un atraso en el desarrollo económico y social del país, puesto que las $\mathrm{TIC}^{50}$, la tecnología,

50 Ley 1341 de 2009, artículo 6. Definición de TIC. "Las Tecnologías de la Información y las Comunicaciones (en adelante TIC), son el conjunto de recursos, herramientas, equipos, programas informáticos, aplicaciones, redes y medios, que permiten la compilación, procesamiento, almacenamiento, transmisión de información como voz, datos, texto, video e imágenes. 
la información y las comunicaciones, permiten la materialización de diferentes derechos fundamentales, entre ellos, la misma salud y, por ende, la vida, la seguridad y defensa nacional, la educación, la libertad de expresión y el trabajo, todos ellos esenciales para el bienestar social.

De otro lado, la deficiencia en la regulación, puesto que los factores que afectan la calidad de los servicios de telefonía móvil también tienen respaldo en la falta de una normativa efectiva que regule de manera eficaz el uso de bloqueadores y amplificadores de señal en el país. Si bien ya existen cimientos de regulación en este aspecto, no se han generado herramientas regulatorias completas que permitan establecer en qué condiciones se puede hacer uso de amplificadores de señal en el país, por ejemplo, en zonas rurales donde no alcanza a vislumbrarse infraestructura de telecomunicaciones.

En relación con el uso de bloqueadores de señal, si bien existen excepciones a su prohibición, es claro que el ejercicio de control de dichos dispositivos es complejo, puesto que no es fácil identificarlos, por lo que se requerirá revisar si es necesario prohibir su comercialización.

Finalmente, si bien los anteriores aspectos afectan la calidad del servicio de las comunicaciones, la insatisfacción de los usuarios de servicios de comunicaciones en Colombia por la mala calidad no solo está soportada, como se explicó anteriormente, en factores de falta de calidad de índole técnica, es decir, temas relacionados con la cobertura del servicio o la deficiencia en la transmisión de datos, sino en factores de índole no técnica, es decir, lo relacionado con la capacidad de atención del operador a las necesidades de los usuarios en aspectos vinculados a la información, las formas de contratación, el reporte de datos, entre otros.

De ahí la importancia de la definición de "calidad de los servicios de comunicaciones" y de comprender, en la determinación de la regulación, todos sus aspectos. Si bien las actividades de vigilancia y control de los servicios en el ordenamiento jurídico colombiano se encuentran circunscritas tradicionalmente a la sanción pecuniaria, al revisarse la efectividad de la imposición de las sanciones en el tiempo, respecto del fin que busca la intervención estatal, el resultado es que la medida no es acorde al fin de la política regulatoria.

El artículo 78 de la Constitución Política de Colombia prescribe:

"La ley regulará el control de calidad de bienes y servicios ofrecidos y prestados a la comunidad, así como la información que debe suministrarse al público en su comercialización. Serán responsables, de acuerdo con la ley, quienes en la producción y en la comercialización de bienes y servicios, atenten contra la salud, la seguridad y el adecuado aprovisionamiento a consumidores y usuarios. El Estado garantizará la participación de las organizaciones de consumidores y usuarios en el estudio de las disposiciones que les conciernen. Para gozar 
de este derecho las organizaciones deben ser representativas y observar procedimientos democráticos internos".

Por su parte, el artículo 334 de esta consagra:

"La dirección general de la economía estará a cargo del Estado. Este intervendrá, por mandato de la ley, en la explotación de los recursos naturales, en el uso del suelo, en la producción, distribución, utilización y consumo de los bienes, y en los servicios públicos y privados, para racionalizar la economía con el fin de conseguir el mejoramiento de la calidad de vida de los habitantes, la distribución equitativa de las oportunidades y los beneficios del desarrollo y la preservación de un ambiente sano ..." (resaltado fuera de texto).

Asimismo, el artículo 365 establece:

"Los servicios públicos son inherentes a la finalidad social del Estado. Es deber del Estado asegurar su prestación eficiente a todos los habitantes del territorio nacional.

Los servicios públicos estarán sometidos al régimen jurídico que fije la ley, podrán ser prestados por el Estado, directa o indirectamente, por comunidades organizadas, o por particulares. En todo caso, el Estado mantendrá la regulación, el control y la vigilancia de dichos servicios. Si por razones de soberanía o de interés social, el Estado, mediante ley aprobada por la mayoría de los miembros de una y otra cámara, por iniciativa del Gobierno decide reservarse determinadas actividades estratégicas o servicios públicos, deberá indemnizar previa y plenamente a las personas que en virtud de dicha ley, queden privadas del ejercicio de una actividad lícita".

Las anteriores disposiciones constitucionales enmarcan como fin estatal la garantía de la calidad de los bienes y servicios ofrecidos, la calidad de vida de los habitantes y la prestación de los servicios públicos de manera eficiente.

Ahora bien, el principio de necesidad aludido por la OCDE señala que los productores de las normas solo deben proponer una regulación, si esta es pertinente para resolver un determinado problema público; adicionalmente, según el principio de proporcionalidad, debe establecerse si los beneficios que representa determinada política regulatoria son mayores que sus costos.

Del análisis económico de la conducta de los proveedores de servicios de comunicaciones frente a las multas impuestas por la entidad de vigilancia y control, teniendo en cuenta que los proveedores de servicios de comunicaciones son naturales maximizadores de riqueza que responden a incentivos, es claro que la multa no es incentivo que conmine al respeto de los derechos de los usuarios.

Lo anterior, puesto que se demostró que la sanción no es un castigo para la ofensa del infractor, pues ni siquiera alcanza a representar el $1 \%$ de utilidad del proveedor que infringió las normas. Lo cual hace evidente que la potestad sancionadora del ente de 
vigilancia y control no se puede catalogar como una herramienta que resuelva la problemática de calidad de los servicios de comunicaciones en Colombia.

Ello, a pesar de que en su ejercicio impere una labor juiciosa de seguimiento a los principios rectores del derecho sancionador, tales como el debido proceso, la legalidad, la tipicidad, la culpabilidad y la discrecionalidad, dentro de los límites de la ponderación y proporcionalidad entre la falta y la sanción pecuniaria.

Consecuentemente, se debe resaltar que son altos los costos en los que incurre el Estado para poder llevar a cabo dicha labor, mientras que los niveles de calidad de los servicios de comunicaciones y la calidad de vida de los habitantes no se ven impactados positivamente gracias a dicha gestión, lo que demuestra que los beneficios de la política sancionadora en materia de comunicaciones no son mayores que los costos que ella implica.

Por otro lado, los incentivos que el regulador podría implementar para conminar a los operadores no pueden fijarse teniendo en cuenta solo el monto de la sanción o estableciendo límites de capacidad sancionatoria extremos, pues lo que se busca es mejorar las prácticas de operación de los proveedores, en beneficio de los usuarios.

Los incentivos al cumplimiento se pueden generar al fortalecer el poder de elección de los usuarios, reduciendo la asimetría de información que estos tienen sobre lo que se debe entender por calidad del servicio de comunicaciones, al establecer indicadores de calificación ramificados teniendo en cuenta las principales fallas del sector.

\section{BIBLIOGRAFÍA}

ACCIARRI, H. A. El análisis económico del derecho de daños. Una aproximación general, en BerNAL Pulido, C. y Fabra Zamora, J. La filosofía de la responsabilidad civil. Estudios sobre los fundamentos filosófico-jurídicos de la responsabilidad civil extracontractual. Bogotá D.C.: Universidad Externado de Colombia, 2013. p. 670.

Agencia Nacional del Espectro. Documento de consulta pública, proceso de selección objetiva para asignación del espectro. Bogotá D.C.: Oficina de Comunicaciones, 2015.

Amador Cabra, L. E. y Grisales, R. La Ley 142 de 1994 desde la perspectiva del análisis económico del derecho, en Contexto, 2011, n. 29.

BARCiA LeHMAN, R. (n.d.). Los efectos de las obligaciones desde la perspectiva del análisis económico del derecho.

Cuadernos de análisis jurídicos. Colección de derecho privado I. Temas de responsabilidad civil. Beristain IlpiÑA, A. Eutanasia: dignidad y muerte. Buenos Aires, Argentina: Depalma, 1991.

Comisión de Regulación de Comunicaciones. Condiciones de compensación automática en servicios de comunicaciones, propuesta CRC, 2013.

COMCEL S.A. [revisado 2 de agosto de 2015]. Disponible en internet: https://www.superfinanciera. gov.co/reportes/pdf

Constitución Política de Colombia, 1991.

Cooter, R., y Ulen, T. Derecho y economía. México D.F.: Fondo de Cultura Económica, 1998.

HurwiCZ, L. But will guard the guardians?, en The American Economic Review, 2008, n. ${ }^{\circ} 98$ (3), pp. 577-585. 
LATORRE, I. La política de mejora regulatoria: oportunidades y desafíos para Colombia, en Revista de Derecho Público, 2014, n. ${ }^{\circ} 33$, p. 33.

MankIW, N. Principios de economía. Madrid: Mc Graw Hill, 2002.

MartíneZ, C. Maximización de la riqueza y asignación de derechos en Richard Posner (Wealth maximization and allocation of rights according to Richard Posner), en Persona y Derecho, 2009, n. $^{\circ} 60$.

OCDE. (n.d.). Disponible en internet: http://www.oecd.org/centrodemexico/laocde/

Ossa Bocanegra, C. Análisis económico de las sanciones administrativas en el derecho de la competencia y del consumo, en Revista de Derecho del Estado, 2015, n. ${ }^{\circ} 35$, pp. 151-179.

Pinzón Camargo, M. Aproximaciones al análisis económico del derecho, 2010.

POLINSKY, A. Introducción al análisis económico del derecho. Barcelona: Ariel S.A., 1985.

Portafolio. 5 de marzo de 2013. Disponible en internet: http://www.portafolio.co/economia/ utilidades-comcel

Posner, R. A. El análisis económico del derecho. México D.F.: Fondo de Cultura Económica, 2007.

SANTOFIMIO GAMBOA, J. O. Reflexiones en torno a la potestad administrativa sancionadora: aplicación en el sector energético, ambiental, de telecomunicaciones y en otros sectores. Bogotá D.C.: Universidad Externado de Colombia, 2014.

SHAVELL, S. Foundations of economic analysis of law. Cambridge: The Belknap Press of, 2004.

Superintendencia de Industria y Comercio. 2 de diciembre de 2012 [revisado 3 de agosto de 2015].

Disponible en internet: http:/www.sic.gov.co/drupal/informe-telefonia-primer-trimestre-2012

Superintendencia de Industria y Comercio. 3 de mayo de 2012 [revisado 2 de junio de 2015].

Disponible en internet: http://www.sic.gov.co/drupal/informe-telefonia-primer-trimestre-2012

TORRADO, M. L. Reflexiones acerca del principio de proporcionalidad en el ámbito del derecho administrativo.

Barranquilla: Universidad del Norte, 2010.

Unión Internacional de Telecomunicaciones. Calidad de los servicios de telecomunicación: conceptos, modelos, objetivos, planificación de la seguridad de funcionamiento - Términos y definiciones relativos a la calidad de los servicios de telecomunicación. UIT, 2011.

VALENCia Suescún, C. Normas vigentes en el sector a partir de la expedición de la Ley 1341 de 2009 y sus deregatorias, en GONZÁLEZ LÓPEZ, E. Comentarios a la Ley de teconologías de la información y las comunicaciones - TIC (Ley 1341 de 2009) Bogotá D.C.: Universidad Externado de Colombia, 2010, p. 1453

\section{Legislación}

República de Colombia. Ley 74 de 1966 "Por la cual se reglamenta la transmisión de programas a través de los servicios de radiodifusión".

República de Colombia. Ley 51 de 1984 "Por la cual se dictan algunas disposiciones en materia de radiodifusión sonora".

República de Colombia. Ley 72 de 1989 "Por la cual se definen nuevos conceptos y principios sobre la organización de las telecomunicaciones en Colombia y sobre el régimen de concesión de los servicios y se confieren unas facultades extraordinarias al Presidente de la República". 
República de Colombia. Decreto Ley 1900 de 1990 "Por el cual se reforman las normas y estatutos que regulan las actividades y servicios de telecomunicaciones y afines".

República de Colombia. Ley 1130 de 1990 "Por el cual se reestructuran el Ministerio de Comunicaciones y algunos organismos del sector administrativo de comunicaciones y se trasladan funciones a otras entidades públicas".

República de Colombia. Ley 37 de 1993 "Por la cual se regula la prestación del servicio de telefonía móvil celular, la celebración de contratos de sociedad y de asociación en el ámbito de las telecomunicaciones y se dictan otras disposiciones".

República de Colombia. Ley 80 de 1993 "Por la cual se expide el Estatuto General de Contratación de la Administración Pública".

República de Colombia. Ley 182 de 1995 "Por la cual se reglamenta el servicio de televisión y se formulan políticas para su desarrollo, se democratiza el acceso a éste, se conforma la comisión nacional de televisión, se promueven la industria y actividades de televisión, se establecen normas para contratación de los servicios, se reestructuran entidades del sector y se dictan otras disposiciones en materia de telecomunicaciones".

República de Colombia. Ley 555 de 2000. "Por la cual se regula la prestación de los servicios de comunicación personal, PCS y se dictan otras disposiciones".

República de Colombia. Ley 1341 de 2009 "Por la cual se definen principios y conceptos sobre la sociedad de la información y la organización de las tecnologías de la información y las comunicaciones -TIC-, se crea la Agencia Nacional del Espectro y se dictan otras disposiciones".

República de Colombia. Ley 1507 de 2012 "Por la cual se establece la distribución de competencias entre las entidades del Estado en materia de televisión y se dictan otras disposiciones".

República de Colombia. Ley 1753 de 2015 "Por la cual se expide el Plan Nacional de Desarrollo 2014-2018 Todos por un nuevo país".

República de Colombia. Decreto 4886 de 2011 "Por medio del cual se modifica la estructura de la Superintendencia de Industria y Comercio, se determinan las funciones de sus dependencias y se dictan otras disposiciones".

República de Colombia. Resolución 3066 de 2011 "Por la cual se establece el Régimen Integral de Protección de los Derechos de los Usuarios de los Servicios de Comunicaciones".

República de Colombia. Resolución 2774 de 2013 "Por el cual se reglamenta el uso de inhibidores, bloqueadores y amplificadores de señales radioeléctricas".

República de Colombia. Resolución 4296 de 2013 "Por la cual se establecen condiciones para la compensación automática a usuarios de servicios de comunicaciones y se dictan otras disposiciones".

\section{Jurisprudencia}

Corte Constitucional, Sala Plena. Sentencia del 8 de agosto de 2001. M.P. Álvaro Tafur Galvis.

Corte Constitucional, Sala Plena. Sentencia del 6 de agosto de 2002. M.P. Manual José Cepeda Espinosa.

Corte Constitucional, Sala Plena. Sentencia del 16 de octubre de 2008. M.P. Rodrigo Escobar Gil. 
Corte Constitucional, Sala Séptima de Revisión. Sentencia T-653 de 2006. M.P. Humberto Antonio Sierra Porto.

Corte Constitucional, Sala Séptima de Revisión. Sentencia T-763 de 1998. M.P. Alejandro Martínez Caballero.

Corte Constitucional, Sala Plena. Sentencia C-393 de 2006. M.P. Rodrigo Escobar Gil.

Corte Constitucional, Sala Plena. Sentencia C-1 189 de 2005. M.P. Humberto Antonio Sierra Porto. 